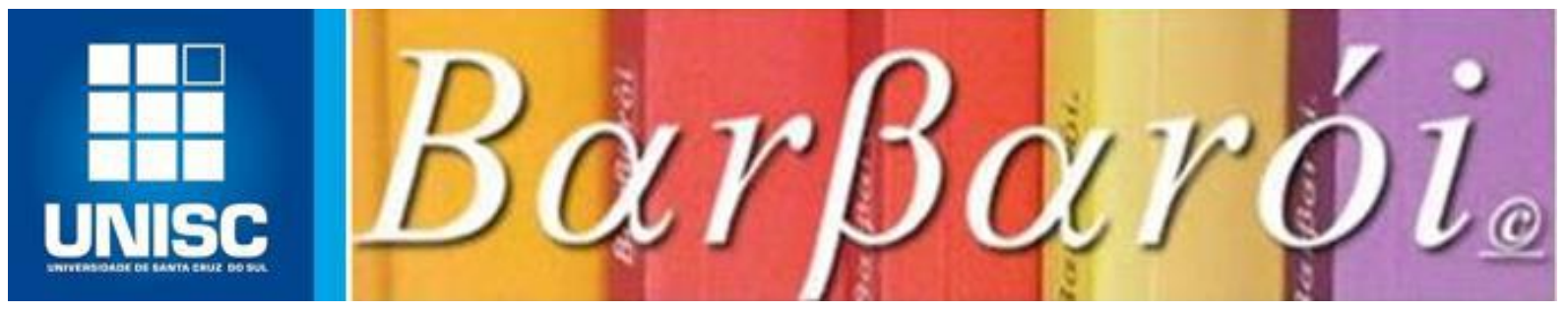

\title{
LIVRE ESCOLHA DA PARTURIENTE PELA ACOMPANHANTE E SEUS ENTRAVES: DESAFIOS PARA A HUMANIZAÇÃO DA ASSISTENCIA AO PARTO E NASCIMENTO
}

\author{
DOI: http://dx.doi.org/10.17058/barbaroi.v0i49.7489
}

\author{
$*$ \\ Claudia Tomasi Vendrúscolo \\ Centro Universitário Franciscano - UNIFRA - Brasil \\ Cristina Saling Kruel \\ Centro Universitário Franciscano - UNIFRA - Brasil
}

$\%$

\section{Resumo:}

O presente artigo teve com proposta investigar a frequência com que as parturientes são acompanhadas durante o parto, com especial atenção aos acompanhantes mais assíduos e as razões que levam uma parturiente estar desacompanhada no momento do parto. Trata-se de uma pesquisa de abordagem quantitativa e qualitativa de cunho descritivo e exploratório, que contou com a participação de 86 puérperas, que se encontravam internadas em uma maternidade pública de um hospital geral durante o mês de agosto de 2013. Para coleta de dados utilizou-se um questionário com perguntas fechadas e abertas. Os depoimentos foram categorizados a partir da Análise de Conteúdo. Os resultados mostraram que $42 \%$ das puérperas tiveram a presença de um acompanhante de sua escolha no parto e dentre estas, o pai do bebê foi o mais frequente, correspondendo a 25\%. A razão mais frequentemente relatada pelas parturientes para estarem desacompanhadas foi a recusa da equipe em aceitar o acompanhante, em $17 \%$ dos casos. Conclui-se que a maioria das puérperas deseja ter um acompanhante durante o parto, mas isso não foi possível para mais da metade das participantes desse estudo por diversas razões que abrangeram o âmbito pessoal da parturiente, organização familiar e organização da equipe de saúde.

Palavras-chave: Maternidade; Parto; Acompanhante.

\section{Introdução:}

O parto é uma experiência importante para a mulher, por vários motivos. Dentre eles, está o seu potencial transformador, pois é o marco entre gestação e puerpério, cuja característica básica é a irreversibilidade, uma vez que o bebê parido não voltará a habitar o ventre materno. Portanto, quando vivenciado plenamente, o parto inaugura novas experiências na vida da mulher e serve como demarcação entre ser filha e tornar-se mãe, entre o bebê 
idealizado e o bebê real, entre o que a mulher sonhou para si e como será de fato, entre tantas outras mudanças que ocorrem de acordo com a cultura da parturiente abrangendo o plano físico, mental, emocional e social (DONELLI, 2003; DONELLI, 2008; MALDONADO, 2002; SOIFER, 1980).

Apesar de o corpo da mulher estar planejado para a reprodução da espécie desde o início da humanidade, os métodos e os costumes que abarcam o parto têm se modificado ao longo do tempo e nas diferentes culturas (MALDONADO, 2002; MOTT, 2002). O parto passou da residência ao hospital, de um evento que envolvia parteiras a uma condição médica, do natural a um evento regrado e medicalizado. Devido as tantas transformações que ocorreram para melhor atender o processo do trabalho do profissional de saúde e também para melhor atender a parturiente e garantir a vida e saúde do bebê, a mulher passou de sujeito a objeto, ou seja, de uma pessoa que podia fazer escolhas em relação a esse momento, a alguém que pouco ou nada decide a respeito do próprio corpo. Por essa e outras razões, que incluem o alto índice de mortalidade materno fetal no Brasil, há um movimento de humanização do parto, preconizado pelo Ministério da Saúde brasileiro, solicitando assistência integral e humanizada à mulher, como uma tentativa de empoderamento da parturiente neste momento (BRASIL, 2001; DONELLI, 2003; HELMAN, 2003; MALDONADO, 2002; MOTT, 2002; NAGAHAMA; SANTIAGO, 2005; TORNQUIST, 2002).

Dentro desse espírito de humanização, tendo em vista toda a complexidade que abarca o momento do parto, considera-se importante a presença de um acompanhante de escolha da mulher para apoiá-la durante o parto, prática esta recomendada pela Organização Mundial de Saúde e que tem sido realizada com êxito em diversos países (DOMINGUES, 2002). No Brasil, o Ministério da Saúde reconhece os benefícios e a ausência de riscos associados à presença do acompanhante no momento do parto, e recomenda que todos os esforços devam ser realizados para garantir que a parturiente tenha uma pessoa de sua escolha para encorajá-la e dar-lhe conforto durante todo o processo do nascimento do seu bebê (BRASIL, 2001). Em 2005 com a instituição da Lei Federal n ${ }^{\circ}$. 11.108, passou a vigorar o direito da parturiente a um acompanhante, indicado pela mesma, durante todo o período de trabalho de parto, parto e pós-parto imediato, nos serviços de saúde do Sistema Único de Saúde - SUS (BRASIL, 2005). Para fortalecer este zelo à parturiente, em 2011, foi lançada no Brasil uma estratégia do Ministério da Saúde chamado Programa Rede Cegonha que visa implementar uma rede de cuidados à mulher, que inclui a assistência humanizada e qualificada no âmbito da atenção obstétrica e infantil, e reitera o direito a um acompanhante de livre escolha da gestante durante o parto (BRASIL, 2011). 
Tal como foi mencionado, dada a relevância da experiência do parto na vida da mulher, e as recentes condutas sugeridas em prol da humanização do parto, a presente pesquisa teve como objetivo averiguar a deferência à Lei Federal 11.108, ou seja, investigar a frequência com que as parturientes são acompanhadas durante o parto em um hospital público, com especial atenção aos acompanhantes mais assíduos e as razões que levam a uma parturiente a estar desacompanhada no momento do parto. Este estudo decorre de uma pesquisa maior que objetivou investigar a experiência da parturiente no que se refere à presença de um acompanhante no momento do parto.

\section{Metodologia:}

\subsection{Delineamento e Participantes:}

O presente estudo é um levantamento, descritivo e exploratório de cunho qualitativo e quantitativo que almeja explicar e interpretar o fenômeno investigativo, observando, registrando, analisando e correlacionando variáveis.

Participaram desde estudo 86 mulheres que estiveram hospitalizadas e tiveram bebê em uma maternidade pública de um hospital geral na cidade de Santa Maria durante o mês de agosto de 2013. A coleta dos dados foi realizada entre as doze horas do dia primeiro de agosto e dezoito horas do dia trinta e um do mesmo mês e todas as foram abordadas pessoalmente pelas pesquisadoras no pós-parto, já acompanhadas dos seus bebês. O hospital atende somente nascimentos de risco habitual e não possui Unidade de Terapia Intensiva Neonatal. Algumas puérperas estavam acompanhadas de familiares e esta não foi variável controlada.

\subsection{Procedimentos de Coleta e Análise de Dados:}

Para a coleta de dados foi utilizado um questionário com perguntas fechadas e abertas. Dentre os aspectos investigados pelo questionário, no presente estudo, foram analisados aqueles que se referiam à frequência com que as parturientes haviam sido acompanhadas durante todo o trabalho ativo de parto, os acompanhantes mais assíduos na sala de parto durante o período expulsivo do parto, e as razões mais frequentes para a falta de acompanhante da escolha da parturiente.

Os dados da pesquisa foram analisados quantitativamente e qualitativamente a partir da Análise de Conteúdo, proposta por Bardin (1996). Os dados quantitativos foram analisados 
de acordo com a freqüência da aparição das informações. Tal tratamento foi dado aos dados derivados das respostas fechadas presentes no questionário.

Os dados qualitativos foram analisados a partir das particularidades e semelhanças entre as respostas das parturientes, das quais emergiram temas que foram convertidos em categorias de análise. Neste trabalho foram analisadas qualitativamente as respostas às perguntas abertas dispostas no questionário.

\subsection{Procedimentos Éticos:}

Esta pesquisa foi submetida ao Comitê de Ética em Pesquisa do Centro Universitário Franciscano e foi aprovada e registrada sob o protocolo 308.401. O questionário foi aplicado após a assinatura do Termo de Consentimento Livre e Esclarecido pelas participantes, garantindo e respeitando as normas de pesquisa com seres humanos, conforme Resolução 196/96 do Conselho Nacional de Saúde (BRASIL, 1996). As puérperas menores de 18 anos assinaram o Termo de Assentimento e o Termo de Consentimento Livre e Esclarecido. A análise dos dados foi de tal maneira que possibilitou a garantia de sigilo e confidencialidade da identidade das puérperas, e foi garantida a desistência das mesmas a qualquer momento do estudo.

\section{Resultados e Discussão:}

\subsection{Benefícios do acompanhante e os motivos que levaram parturientes a estar desacompanhada no momento do parto:}

A hospitalização da assistência ao nascimento tem sido assinalada como grande obstáculo à humanização (BARBOSA; GUALDA, 2009). O parto no ambiente hospitalar, em muitos casos, aumenta o estresse da mulher por ser um local desconhecido, no qual a parturiente é cuidada por pessoas que também são desconhecidas, perdendo a ligação com o espaço familiar em um momento que é tão exclusivo e especial na sua vida (RAMALHO, 2009). Então, com a institucionalização do parto houve o afastamento da família e da rede de apoio no processo do nascimento, pois a estrutura física e os hábitos hospitalares não foram planejados para assistir as parturientes, mas sim para as necessidades dos profissionais de saúde (DINIZ, 2001; OMS, 1996). Com isso, grande parte das mulheres passou a permanecer internada em quartos coletivos, sem privacidade, e tornaram-se passivas diante das regras e 
foram privadas da presença de uma pessoa de sua confiança e intimidade para apoiá-las (BRUGGEMANN; PARPINELLI; OSIS, 2005). O parto passou a ser um "rito de passagem", cheio de rotinas e normas de comportamento que são definidas pela instituição hospitalar (DINIZ, 2001) destituindo as mulheres de sua privacidade, do poder de decisão sobre como e onde deseja que ocorra o parto e quem a acompanha durante esse processo (TORNQUIST, 2002).

As participantes deste estudo tinham idade entre 14 e 43 anos, com média de 18 anos. O número de filhos das participantes, incluindo o bebê recém-nascido, variou entre um e oito, sendo que $46 \%$ das parturientes eram primíparas, $27 \%$ tinham dois filhos; $14 \%$ tinham três filhos e $13 \%$ tinham quatro filhos ou mais.

Quanto ao tipo de parto, 84\% das puérperas que foram abordadas tiveram parto vaginal, também chamado de normal e $16 \%$ haviam realizado o parto cesáreo. No que se refere aos procedimentos realizados no parto, $45 \%$ das puérperas relataram ter sido submetidas à episiotomia e em $5 \%$ dos casos foi utilizado o fórceps para a retirada do bebê, enquanto que para os demais nascimentos, que correspondem a $50 \%$, não foi necessário nenhum tipo de procedimento. Também foram constatadas intercorrências em $26 \%$ das puérperas no momento do parto, sendo que $20 \%$ dessas puérperas relataram terem sofrido lacerações na região vaginal e $6 \%$ relataram terem tido um parto demorado.

Pesquisas recentes têm mostrado que a presença do acompanhante e o apoio emocional oferecido pelo mesmo proporcionam bem estar físico e emocional à parturiente favorecendo uma boa evolução nesse período, diminuindo os índices de partos complicados, auxiliando a mulher a suportar melhor a dor e a tensão do trabalho de parto e parto, podendo, inclusive, diminuir o tempo de hospitalização mãe-bebê e a ocorrência de depressão pós-parto (BRASIL, 2010; SABINO, 2010). Deve-se observar que o movimento de humanização do parto em prol da parturiente, tem se mostrado positivo para a mesma.

No que se refere à presença de um acompanhante da escolha da parturiente durante o seu parto, $42 \%$ das puérperas disseram que foram acompanhadas e $58 \%$ disseram que não tiveram a presença do acompanhante de sua escolha. Cabe destacar que $90 \%$ das puérperas que responderam a pesquisa desejavam ter um acompanhante de sua escolha e $10 \%$ disseram que preferiam estar na companhia somente da equipe de saúde. É importante, ainda, salientar que das puérperas participantes que não foram acompanhadas (58\%), 48\% achavam importante a presença do acompanhante e, gostariam de estar acompanhadas no momento do parto, porém não tiveram o acompanhante. Portanto, do grupo de mulheres desacompanhadas, $10 \%$ estavam satisfeitas de estar somente com a equipe. Pode-se perceber que a Lei Federal 
de 2005 de domínio público $\mathrm{n}^{\circ}$. 11.108, já mencionada anteriormente, que configura a humanização da assistência ao parto e ao nascimento com caráter menos intervencionista e que aceita a possibilidade de presença do acompanhante durante o parto, não é totalmente atendida, tendo em vista que neste estudo menos da metade das participantes foram acompanhadas por uma pessoa de sua escolha durante o parto.

As parturientes que foram acompanhadas durante o parto por alguém da sua escolha, foram questionadas a respeito do acompanhante e $25 \%$ delas respondeu que foi acompanhada pelo pai do bebê; $8 \%$ por sua irmã; $6 \%$ respondeu que estava com a avó paterna do bebê; $3 \%$ estava com sua mãe; e as demais, que correspondem a $6 \%$ foram acompanhadas por tias, madrinhas ou estagiária do curso de psicologia. A estagiária do curso de psicologia foi considerada acompanhante de livre escolha da parturiente neste caso, pois habitualmente essa não acompanha o parto em período expulsivo e o faz somente quando solicitada pela parturiente. Salienta-se que dentre as participantes que foram acompanhadas pelos pais dos bebês, que corresponde a $25 \%$ da amostra, $5 \%$ referiram-se aos casos em que os pais dos bebês desejavam acompanhar o parto, contrariando o desejo da parturiente.

As puérperas que relataram não terem sido acompanhadas durante o parto (58\%) foram questionadas a respeito do motivo que as levou a estarem desacompanhadas e $17 \%$ disseram ter havido impedimento pela equipe de saúde, em alguns casos, sem explicitar motivo da não aceitação do acompanhante. Isso fez com que as parturientes deixassem de estar acompanhadas por uma pessoa de sua escolha no momento do parto. A respeito disso, as puérperas verbalizaram: A equipe disse que não podia ter acompanhante (E 20); Em cesariana pode dar risco de infecção, disse a enfermeira (E 51); Disseram que não podia ter acompanhante no parto cesárea, somente no parto normal (E 79); Falei com a enfermeira, ela disse para falar com a doutora. A enfermeira disse que eu tinha direito. Falei com a médica e ela disse que não podia (E 83).

As falas dessas puérperas denunciam que, mesmo a parturiente desejando a presença do acompanhante e comunicando a equipe sobre seu desejo, em alguns casos, este não teve permissão para entrar. A inserção do acompanhante no processo de trabalho de parto e parto emerge da necessidade de preencher a estranheza e a solidão da parturiente devido à institucionalização do nascimento. No entanto, apesar da importância do acompanhante ser reconhecida, a aceitação do mesmo na rotina hospitalar ainda tem sido alvo de muitas discussões (STORTI, 2004). A presença do acompanhante está mais de acordo com a filosofia de cada Unidade Obstétrica, por isso, em alguns locais é estimulada, em outros não é tolerada ou há restrições (HOTIMSKY, 2013). 
De acordo com a resposta da puérpera E 83, pode-se perceber que as restrições na presença do acompanhante deflagram as relações hierárquicas entre profissionais da saúde, fato este apresentado também na pesquisa de Nakano, et al (2007) que mostrou que o médico é a figura central, cabendo à equipe colaborar com ele e à parturiente ser paciente, passiva e colaborativa. Além disso, o acompanhante deve ajudá-la a manter-se nesta posição apenas, tendo uma participação limitada, se sentindo ignorado e incapaz. Bruscato, et al (2004) observa que ainda há instituições e profissionais que avaliam o paciente de maneira independente e executando seus planos de tratamento como uma "camada adicional" de serviços. Logo, não há um trabalho coordenado por parte dessa equipe e uma identidade grupal, ou seja, o médico, em geral, é responsável pela decisão do tratamento, e os outros profissionais vão se adequar à demanda do paciente e às decisões do médico referente a este.

Em um estudo randomizado controlado realizado por Bruggemann; Osis; Parpinelli (2005) em um centro obstétrico de uma maternidade em Campinas, SP foi constatado que, a princípio, os profissionais de saúde, não tendo experiência com a presença do acompanhante no momento do parto, pensaram que poderiam ocorrer muitos problemas e tensão com a presença do mesmo. No entanto, constataram que o apoio do acompanhante foi importante e não observaram problemas. Na presença do acompanhante ocorreram mudanças positivas na assistência, houve apoio emocional à parturiente ocasionando mais tranquilidade, segurança e satisfação para ela. Em outro estudo realizado com profissionais de saúde que trabalhavam no Centro de Parto Normal em São Paulo efetivado por Hoga e Pinto (2007) constatou-se que os sentimentos apreensivos, crenças e valores identificados nos profissionais, quanto ao acompanhante ser um obstáculo no processo de parto ou pela sala de parto ter um espaço físico limitado, não comportando o acompanhante, têm prejudicado a inclusão do acompanhante no parto. No entanto, após observarem várias parturientes acompanhadas verificou-se que as crenças eram infundadas, e que os serviços de saúde deveriam incorporar novos valores. A experiência mostrou que a presença do acompanhante traz reflexos positivos nos vários âmbitos do nascimento e parto.

Outro fator importante para a ausência de acompanhante no momento do parto foi por falta de tempo para que o acompanhante se integre à equipe de saúde. Um total de $13 \%$ das puérperas participantes relatou esse motivo, terem tido um parto rápido: Não deu tempo do pai do bebê entrar, vestir a roupa (E 6); Não deu tempo. Foi pegar a máquina. Ganhei na sala de avaliação (E 22); Não deu tempo, quando ele viu (pai do bebê) estavam me levando para sala (E 23); Não deu tempo, ganhei na sala de avaliação (E 64). 
Sabe-se que certas situações não são habituais em uma maternidade, e por certo, se as parturientes não forem bem orientadas quando chegam à Unidade, acabam por ter seu bebê acompanhadas somente da equipe de saúde. Em pelo menos três situações pode ocorrer esse contratempo: a primeira é quando gestante chega ao hospital parindo o bebê e não há tempo para os procedimentos padrão, a segunda ocorre quando a parturiente permanece por horas em trabalho de parto e na ocasião da avaliação se observa que o parto está avançado e então o nascimento acontece neste momento, como é apontado na resposta das puérperas E 22 e E 64 . A terceira situação ocorre quando a parturiente, após horas em trabalho de parto, é levada às pressas para o Centro Obstétrico e não há tempo para o acompanhante escolhido vestir-se adequadamente, conforme as respostas das puérperas E 6 e E 23. As duas últimas situações mencionadas ainda podem ser agravadas pelo fato da parturiente e acompanhante não serem informados sobre o direito de acompanhamento durante o parto. Se ambos fossem instruídos sobre o seu direito, possivelmente, as duas últimas situações não ocorreriam. Parturiente e acompanhante teriam as orientações necessárias de como proceder se ocorresse um caso ou outro, assim o acompanhante poderia estar dando assistência à parturiente no momento do parto.

De acordo com o relato das puérperas, verifica-se que o atendimento centrado no ser humano com suas crenças e valores fazem com que novas políticas devam ser implantadas, para que se possa ter um atendimento biopsicossocial. São necessárias mudanças para a melhoria de assistência ao parto e na sua humanização visto que o atendimento ainda é centrado no biológico, no modelo biomédico de saúde/doença (BEZERRA, 2006). Percebese, de certa forma, que o parto, apesar de ser um evento natural e estar presente na vida de todo o ser humano "tem sido tratado como um evento que necessita ser dominado e controlado" (DONELLI, 2008, p. 172).

Tendo discutido duas razões mais frequentes para a ausência do acompanhante, que foi a recusa da equipe em aceitar o acompanhante, e a pressa, que aparentemente foge ao controle da equipe de saúde e da gestante, o fator desconhecimento da mulher e de sua família quanto ao seu direito da presença do acompanhante apareceu como terceira resposta. Este fator foi mencionado por $10 \%$ das puérperas participantes que relataram também a falta de incentivo da equipe de saúde: Ninguém avisou que poderia entrar alguém (E 16); Não sabia que dava para ter acompanhante (E 40); As enfermeiras não falaram nada (E 59); Calculo que não desse tempo ou faltou atenção deles chamarem minha mãe (E 66).

Não é raro ver usuários dos serviços de saúde desinformados quanto aos seus direitos sendo agentes passivos diante das mais diversas situações conforme manifestado pela 
puérpera E 40. Considera-se que a experiência do parto depende de uma série de condições intrínsecas à mulher e à gestação, podendo haver consequências positivas ou negativas que relacionam-se ao sistema de saúde, como acolhimento ou falta deste, fornecimento de informações e orientações ou ausência das mesmas, assistência humanizada ou desumanizada. Em outras palavras, há um conjunto de cuidados, medidas e atividades que objetivam oferecer à parturiente vivenciar a experiência do trabalho de parto e parto de forma que ela sinta protagonista desse processo (BRASIL, 2001). Ademais, conforme já dito, a presença do acompanhante de escolha da parturiente, considerado por alguns profissionais como problema, pode se converter numa ocasião que seja benéfica para serviço (BRUGGEMANN; PARPINELLI; OSIS, 2005). É importante ressaltar que se não houvesse a desinformação da parturiente, como no caso da puérpera E 40 ou a falta de atenção da equipe demonstrada nas respostas das puérperas E 16, E 59 e E 66, a experiência do parto poderia ter sido mais acolhedora a estas mulheres.

Além disso, esta pesquisa deflagrou o fato de que algumas parturientes não desejam estar acompanhadas durante o momento do parto, senão pelos profissionais da saúde. As mulheres que recusaram a presença de um acompanhante da sua escolha, o que aconteceu em $9 \%$ dos casos, referiram não valorizar esta presença para a redução dos sintomas físicos e psicológicos e sinalizavam o anseio por privacidade: Preferi ficar sozinha (E 11); Não queria ninguém comigo naquele momento (E 41); Não quis nenhum acompanhante. A dor que a gente sente só a gente sente, ele (pai do bebê) não vai sentir e não vai poder fazer nada (E 50); Eu não quis. Queria estar sozinha (E 72).

Por estas respostas, pode-se perceber que nem todas as parturientes que estavam sem acompanhante no momento do parto se sentiam desacompanhadas, desprotegidas, solitárias. Hotimsky e Alvarenga (2002) constataram essa mesma conduta em algumas mulheres em uma pesquisa realizada em vários serviços de saúde de atendimento obstétrico em São Paulo. Havia mulheres que traziam o desejo de privacidade neste momento do parto, queriam estar apenas com a equipe responsável e se sentiam bem acompanhadas por estes profissionais.

Aliás, a preferência por ficar somente na presença da equipe de saúde e, em especial, sem a presença do pai do bebê, pode representar duas posições: a primeira se refere a um ideal feminista de que o parto é um assunto feminino e a segunda traz uma visão machista, a partir da qual se entende que o cuidado com a criança é um trabalho da mulher no qual o homem não almeja se envolver (DOMINGUES, 2002). Pode-se inferir que a fala das puérperas E 11, E 41 e E 72 denotam o ideal feminista, na qual a mulher é capaz de enfrentar este momento do parto sem a presença masculina ou de outro acompanhante íntimo. Representam mulheres 
com certa autonomia para decidir e enfrentar as dores sozinhas, pois o bebê vai sair do seu ventre e não de outro, assim, a equipe com seus procedimentos bastam a seu entender. Além disso, a parturiente E 50 mostra que não é possível compartilhar com o pai da criança a dor sentida por ela e quando verbaliza "[ele] não vai poder fazer nada" remonta a posição machista, exposta anteriormente.

Outro aspecto a ser observado é que nas horas que antecedem o parto, muitas mulheres vivem a dor mais intensamente e a mesma se dá de diferentes formas, isto é, para cada mulher é distinta a sensibilidade. A dor é perpassada pela emoção e dependo da forma como essas mulheres foram preparadas para o parto, sua história de vida, cultura, relação com sua mãe, tudo isso, têm um significado e interfere nas reações que precedem o parto (SZEJER, 1997). Por isso, a dor tem um significado pessoal, social e cultural (MALDONADO,2002). É importante também destacar que o parto normal é percebido por um grande número de mulheres como sinônimo de dor e sofrimento, devido, em alguns casos, ao parto ser cercado de mitos e crenças. Por muito tempo, as dores que as mulheres sentiam no parto tiveram implicação religiosa, a Bíblia Sagrada contribui para isso, quando aponta que a mulher deve sofrer pela expiação do pecado original que cometeu e que seu filho é fruto do pecado, assim a mulher deve passar pela provação do castigo que é merecedora (BEZERRA; CARDOSO, 2006; SPINK, 2013; PERROT, 2012). Esse legado da mulher é bem antigo, tem início com Aristóteles no século IV a.C. quando se enfatizava a autoridade paterna e marital, sendo reiterado pela Teologia Cristã que fala da criação da mulher, responsável pelo pecado e detentora da maldição. Cabe considerar que ainda se observa que esse estigma da mulher está presente nos dias atuais. Passado de geração para geração, incutido por meio da religião, a mulher sente as dores do parto como punição, e deve se submeter passivamente a pena imposta, sem questionar, revoltar-se ou praticar algo que amenize esse processo do parto. Por ser mulher tem que passar por esse sofrimento, fato esse que vai de encontro às políticas de humanização do parto que visam atenuar esse momento, trazendo mais tranquilidade à mulher.

Por fim, ainda foram observados casos em que não havia acompanhante da escolha da parturiente para acompanhá-la ou a recusa do acompanhante presente, que somam $9 \%$ dos casos: Não pedi. O marido não pode vir por que trabalhava (E 5); Por que o pai (pai do bebê) estava viajando e a avó materna (bisa do bebê) estava muito nervosa. Preferi ir sozinha (E 9); No momento não tinha nenhum acompanhante que pudesse me acompanhar. Se tivesse outra pessoa sim (E 12); Marido foi trabalhar e levar os filhos no colégio. Não deu tempo ganhei na sala de avaliação (E 19); Por que ninguém da família teve coragem (E 31); 
Ninguém teve coragem de ver o parto (E 61); Meu marido não quis entrar. Entrou, mas saiu (E 76).

É necessário mencionar que todas estas puérperas achavam importante a presença de um acompanhante no parto, no entanto, apesar das expectativas de serem acompanhadas, elas não tinham ninguém que as acompanhasse nesse momento. Não raro é encontrar mulheres que por um motivo ou outro não tem alguém de sua intimidade que as acompanhe durante o período de hospitalização e no parto. Nesses casos, poderia se pensar na assistência das doulas, profissionais treinadas, preparadas para acompanhar e auxiliar gestantes durantes o período de gestação, pré, durante e pós-parto (SOUZA; DIAS, 2010; LEÃO; OLIVEIRA, 2006). No entanto, sabe-se que esta realidade da assistência das doulas ainda é restrita a uma minoria, que tem condições de arcar com as despesas de manter essa profissional.

Outro aspecto a ser observado é o de que todos os que circundam a gestante, principalmente o pai do bebê, sentem-se ansiosos (SOIFER, 1980). Por isso, os profissionais devem ter um olhar para além da parturiente, atendendo também o acompanhante, considerando suas necessidades emocionais de amparo e orientando-o, quando possível, para que desempenhe um papel de provedor de suporte. $\mathrm{O}$ acompanhante também está vivenciando um momento especial e precisa ser visto dessa forma, e ser acolhido nesse contexto assistencial. Por certo, experimentará um sentimento de confiança e valorização da sua função, que refletirá de maneira positiva no desempenho de suas atividades de conforto físico e emocional a parturiente (BRUGGEMANN; PARPINELLI; OSIS, 2005).

Sobre este último grupo de puérperas que esteve desacompanhada no momento do parto, foi possível observar que durante a aplicação dos questionários, de modo geral, as mulheres estiveram acompanhadas antes e depois do parto, no entanto, não tiveram nenhum familiar que quisesse as acompanhar no período expulsivo. Observou-se que o familiar não conseguia lidar com essa nova situação e acabou por sentir-se angustiado e com medo, e por mais que as parturientes pedissem e dissessem que a presença deles era importante, os mesmos não conseguiram acompanhá-las. Neste período da hospitalização, o acompanhante também se encontra fragilizado, e dependendo da forma como se dá o transcorrer do trabalho de parto ele se angustia e não consegue dar o suporte necessário à parturiente, ou seja, não consegue assisti-la. 


\subsection{Estar acompanhada durante o parto: $o$ desejo por uma companhia íntima feminina:}

As respostas das participantes desse estudo mostraram que nas parturientes que foram acompanhadas, o acompanhante mais frequente no momento do parto foi o pai do bebê. Contudo, na falta deste, em nenhum momento as parturientes desejaram a presença de outro homem, ao contrário, preferiram uma mulher, seja ela sua mãe, sogra, cunhada, tia, irmã ou amiga. O mais interessante disso, é que este fato corrobora o cenário que ocorria há décadas e até séculos, que aponta o desejo da presença de uma companhia íntima, alguém que a parturiente se afeiçoava, em especial, uma presença feminina.

Sobre isso, Spink (2013) salienta que os homens são envolvidos nos partos eventualmente por seu papel de companheiro da parturiente ou de pai do bebê. Por essa colocação e tendo em vista os dados da presente pesquisa, é possível inferir que o pai da criança acompanha, na maioria dos casos, por ser o pai de direito, por ser o marido de direito e não pelo desejo da parturiente. Esse registro pode ser feito tendo em vista as respostas das parturientes que demonstraram que dentre as $42 \%$ mulheres que estiveram acompanhadas, $25 \%$ tiveram a presença do pai da criança e $16 \%$ de outras mulheres.

Outro dado que é importante ressaltar é que muitos dos pais dos bebês que estavam entre os $25 \%$, estiveram presentes durante o parto por desejo deles em assistir o parto e não da parturiente. Pode-se compreender, então que ao escolher o seu acompanhante no momento do parto, as parturientes predominantemente escolheram uma mulher. Porém, as transformações sociais ocorridas nas últimas décadas tornaram o homem cada vez mais presente nas atividades de cuidados aos filhos, o que gerou neste o desejo de acompanhar todos os momentos, inclusive o nascimento. Por muitas décadas o pai foi retirado da cena do parto, no entanto, atualmente com o crescente interesse do pai pelos filhos e instituição da nova Lei de incentivo do acompanhante, muitos homens têm acompanhado e apoiado suas mulheres nesse momento importante da vida do casal (RAMALHO, 2009).

Stern (1997) salienta que o novo pai pode participar das muitas formas de cuidado, dar apoio à mulher, inclusive como cuidador primário no momento do parto e dar apoio emocional, o que segundo Motta e Crepaldi (2005), configura-se mediante a aproximação da parturiente de forma carinhosa, enunciação de palavras de encorajamento e de elogios. Além disso, Szejer e Stewart (1997) sugerem que para que ocorra a concepção e o nascimento de um filho é preciso três, pai-mãe-filho e, um depende do outro, e sem que os três tenham o desejo, não haverá nascimento. 
Entre outras razões, quando uma mulher escolhe alguém do mesmo sexo para acompanhá-la no processo do parto, não se está descartando a relevância que o pai do bebê tem para que se chegue efetivamente no momento do parto e nem o apoio que ele pode proporcionar à mulher. Perrot (2012) evidencia que por muitos séculos a mulher sofreu opressão e submissão em relação à igreja, ao Estado ao marido, entre outros. Consoante com estes fatos acredita-se que isso fez com que houvesse uma identificação maior entre as mulheres no transcorrer dos tempos, por ser do mesmo sexo e passar pelas mesmas situações, principalmente as que dizem respeito à maternidade e as implicações que a mesma traz para a mulher. Neste momento que a parturiente está vivenciando, a experiência de sua mãe, da irmã que já teve um filho, da amiga e ou da cunhada, faz com que a mesma se sinta mais tranquila, acolhida, principalmente quando essas tiveram experiências positivas em seus partos. Percebe-se que, apesar da maior independência feminina na maioria das culturas, essa afinidade entre o sexo feminino ainda não se esgotou. As mulheres ainda buscam umas as outras em certas situações que se assemelham, como no caso do parto.

Cabe salientar que muitas políticas de saúde vêm sendo preconizadas em prol de uma assistência humanizada à mulher. Essas políticas ditam como deve ser o parto. A ONG ReHuNa, surge com uma proposta que vai de encontro do grande número de cesarianas e das rotinas hospitalares como, tricotomia, episiotomia, ocitocina, etc (CARNEIRO, 2013). O Programa Rede Cegonha é outra proposta do Ministério da Saúde que dispõe de uma rede de cuidados às mulheres e aos bebês. Em vista disso, Duarte (2003), salienta que deve-se buscar a singularidade e não a universalidade. As mulheres buscam não apenas mais um parto nas instituições, mas o parto (CARNEIRO, 2013; DONELLI; LOPES, 2013). Assim, faz-se necessário pensar que a parturiente deve poder decidir sobre a melhor maneira de parir e com isso, é possível pensar que o parto cesáreo pode ser humanizado em alguns casos, assim como o parto desacompanhado também, desde que a equipe de saúde seja capaz de tranqüilizar a parturiente. É importante ressaltar que as políticas são pensadas e desenvolvidas para benefício da população e tem proporcionado grandes progressos nesse âmbito da gestação e parturição. Entretanto, a pluralidade com que as ações são implementadas pode se sobrepor à singularidade da experiência pessoal. No que diz respeito à experiência pessoal e ao desejo de cada mulher, somente os encontros entre a parturiente e a equipe de saúde e a sensibilidade e escuta ativa dos profissionais quanto as demandas dela, poderão prover a atenção respeitosa ao nascimento. 


\section{Considerações finais:}

O objetivo deste artigo foi analisar a frequência com que as parturientes foram acompanhadas durante o parto em um hospital municipal, com especial atenção aos acompanhantes mais frequentes, bem como as razões que levam uma parturiente estar desacompanhada no momento do parto, e alguns dados merecem ser retomados para a finalização deste artigo.

Pode-se perceber que apesar da maioria das puérperas acharem importante a presença do acompanhante e desejarem sua presença no parto, mais da metade das participantes não foram acompanhadas no momento do parto por motivos diversos: não deu tempo, pressa, recusa da parturiente em ter um acompanhante; recusa da equipe por desinformação da parturiente e/ou ausência de incentivo da equipe; ausência do acompanhante e por recusa do acompanhante e uma minoria dispensa sua presença. Em resumo, percebe-se que nem sempre o desejo de estar acompanhada é realizado ou incentivado.

Entre as puérperas participantes que tiveram a presença do acompanhante no momento do parto, o acompanhante mais frequente foi o pai do bebê. No entanto, nos casos em que o marido não se fazia presente, não era outro homem que elas escolhiam, mas sim desejavam a companhia de alguém do sexo feminino, com quem tinham afeição. Esse fato remete ao início da história da assistência ao parto quando as mulheres tinham seus bebês acompanhadas das parteiras junto às mulheres de sua família.

É preocupante saber que muitas ainda são as parturientes que não recebem a devida atenção e/ou até desconhecem seus direitos diante desse momento tão importante que é o nascimento de um filho. Os profissionais de saúde precisam estar conscientes da importância desse momento para melhor atender essa demanda e ter um olhar para a singularidade da parturiente ao invés da universalidade. Não faz parte do objetivo deste estudo esgotar as reflexões sobre o assunto, muito pelo contrário, a ideia é tentar chamar atenção para esse tema do acompanhante de escolha da parturiente no momento do parto, uma vez esse assunto visa à humanização da assistência ao parto e nascimento.

Este estudo contribui para que o assunto do acompanhante no parto seja cada vez mais valorizado pelos profissionais da saúde. Por isso, acredita-se que os resultados deste estudo poderão colaborar para a suposição de novas formas de organização dos serviços, e de práticas assistenciais na atenção ao parto tendo em vista a promoção da saúde, a humanização da assistência e a maior satisfação das parturientes atendidas nos serviços de saúde, assim configurando uma oportunidade para qualificar o atendimento multidisciplinar nas instituições 
de saúde. Essa temática também instiga as mulheres a se empoderar sobre as atitudes referentes ao seu corpo e os entornos que as envolvem.

Deve haver uma produção científica mais ampla sobre essa temática para que haja uma atenção ao parto menos intervencionista, para que ocorram experiências positivas e enriquecedoras às mulheres, já que ainda há alguns profissionais de saúde que resistem a mudanças no modelo assistencial. Considera-se, dessa forma, que falta muito para compreender sobre o assunto, pois há muito que investigar ainda, principalmente nas questões que atravessam a não realização de um parto mais humanizado, pois ainda enfrenta-se resistência da equipe em relação à presença do acompanhante.

\title{
FREE CHOICE OF THE PARTURENT BY THE ACCOMPANYER AND HIS ENTRAVES: CHALLENGES FOR THE HUMANIZATION OF ASSISTANCE TO BIRTH AND BIRTH
}

\begin{abstract}
:
The current article proposes to investigate the frequency in which women are accompanied during the childbirth, paying special attention to the most assiduous accompanying and the reasons that lead the parturient of being unaccompanied at the moment of childbirth. It is about a research with quantitative and qualitative approach with descriptive and exploratory nature, which counted with the participation of 86 parturients, which were hospitalized at the maternity of a public general hospital during the month of August 2013. To the collection of data was used a questionnaire with closed and open questions. The results indicated that $42 \%$ of the parturients had the presence of a companion of his own choice at the childbirth and among the parturients, the father of the child was the most attendant, corresponding to $25 \%$. The most frequent reason to the parturient to be unaccompanied was the refuse of the medical staff to accept companion, representing $17 \%$ of the cases. It concludes that the majority of the parturients desire to have a companion during the childbirth, but it was not possible to half of the participants of this study by many reasons that cover the personal ambit of the parturient, familiar organization and the medical staff organization.
\end{abstract}

Keywords: Maternity; Parturition; Companion.

\section{LIBRE ELECCIÓN DE LA PARTURIENTE POR EL ACOMPAÑANTE Y SUS ENTRAVES: DESAFÍOS PARA LA HUMANIZACIÓN DE LA ASISTENCIA AL PARTO Y NACIMIENTO}

\section{Resumen:}

Se propone este artículo para investigar la frecuencia con la que las madres son acompañadas durante el parto, con especial atención a los compañeros más asiduos y las razones por las cuales una parturienta no es acompañada en el parto. Este es un enfoque de investigación cuantitativa y cualitativa de carácter descriptivo y exploratorio en la naturaleza, que contó con la participación de 86 mujeres puerperal, que fueron hospitalizadas en una maternidad pública en un hospital general durante el mes de agosto de 2013. Para la recopilación de datos se utilizó un cuestionario con preguntas cerradas y abiertas. Los informes fueron clasificados a partir del análisis de contenido. Los resultados mostraron que $42 \%$ de las madres tenían la presencia de un acompañante de su elección en el parto y entre estos, el padre del bebé fue el 
más frecuente, representando el 25\%. La razón más frecuente para la parturienta no ser acompañada fue la negativa da equipo de aceptar el acompañamiento, en el 17\% de los casos. Se concluye que la mayoría de las mujeres quieren tener un acompañante durante el parto, pero esto no fue posible en más de la mitad de las participantes en este estudio por varias razones que abarcan el ámbito personal de la mujer, la organización familiar y organización del equipo de salud.

Palabras Clave: Maternidad; Parto; Acompañamiento.

\section{Referências:}

BARBOSA M. M. A.; GUALDA, D. M.R. O cuidado a saúde materna no Brasil e o resgate do ensino de obstetrizes para assistência ao parto. Rev Latino-am Enfermagem, 2009 março-abril; 17(2) [periódico na Internet] [acessado 2013 abr 15] Disponível em: http://www.redalyc.org/articulo.oa?id=281421907020.

BARDIN, L. Análise de Conteúdo. 4ª ed. Lisboa /Portugal: Edições 70, 2010.

BEZERRA M. G. A.; CARDOSO, M. V. L. M. L. Fatores culturais que interferem nas experiências das mulheres durante o trabalho de parto e parto. Revista Latino-Americana de Enfermagem, Ribeirão Preto, v. 14, n. 3, Jun 2006. [periódico na Internet] [acessado 2013 abr 16]. Disponível em: http://www.scielo.br/pdf/rlae/v14n3/v14n3a16.pdf

BRASIL. Conselho Nacional de Saúde. Resolução 196 de 10 de outubro de 1996. Dispões das normas e os regulamentos de pesquisa com seres humanos. Brasília, 1996.

Ministério da Saúde. Secretaria de Políticos de Saúde. Área Técnica de Saúde da Mulher. Parto, aborto e puerpério: assistência humanizada à mulher/ Ministério da Saúde, Secretaria de Políticas de Saúde, Área Técnica da Mulher. - Brasília: Ministério da Saúde, 2001.

Lei $\mathbf{n}^{\mathbf{0}}$. 11.108, de 7 de Abril de 2005. Altera a Lei no 8.080, de 19 de setembro de 1990, para garantir às parturientes o direito à presença de acompanhante durante o trabalho de parto, parto e pós-parto imediato, no âmbito do Sistema Único de Saúde - SUS. Diário Oficial da União, Brasília, 2005.

Ministério da Saúde. Secretaria de Atenção à Saúde. Núcleo Técnico da Política Nacional de Humanização. HumanizaSUS: visita aberta e direito a acompanhante / Ministério da Saúde, Secretaria de Atenção à Saúde, Núcleo Técnico da Política Nacional de Humanização. - 2a ed. 4. reimp. - Brasília: Ministério da Saúde, 2010.

Ministério da Saúde. Rede Cegonha. Atenção integral a saúde da mulher e da criança. Estratégia de qualificação da atenção obstétrica e infantil. - Brasília: Ministério da Saúde, 2011.

BRUGGEMANN, O. M.; PARPINELLI, M. A.; OSIS, M. J. D. Evidências sobre o suporte durante o trabalho de parto/parto: uma revisão da literatura. Caderno de Saúde Pública 2005, 21(5): 1316-1327 [periódico na Internet] [acessado 2013 jun 26]. Disponível em: http://www.scielo.br/scielo.php?script=sci_arttext\&pid=S0102-

311X2005000500003\&lng=en. http://dx.doi.org/10.1590/S0102-311X2005000500003. 
BRUSCATO, W. L.; KITAYAMA, M. M.; FREGONESE, A. A.; DAVID, J. H. O trabalho em equipe multiprofissional na saúde. In: BRUSCATO, W. L.; BENEDETTI, C.; LOPES, S. R. A. A prática da psicologia hospitalar na Santa Casa de São Paulo: novas páginas em uma antiga história. São Paulo: Casa do Psicólogo, 2004, p. 33-42.

CARNEIRO, R. G. Dilemas antropológicos de uma agenda de saúde pública: Programa Rede Cegonha, pessoalidade e pluralidade. Interface (Botucatu), Botucatu , v. 17, n. 44, Mar. 2013 [periódico na Internet] [acessado 2013 out 10]. Disponível em: http://www.scielo.br/scielo.php?script=sci_arttext\&pid=S1414$32832013000100005 \& \operatorname{lng}=\mathrm{en} \& \mathrm{nrm}=\mathrm{iso}$

DINIZ, C. S. G. Entre a técnica e os direitos humanos: possibilidades e limites da humanização da assistência ao parto. São Paulo: Faculdade de Medicina da Universidade de São Paulo. 2001. 264 p. Tese (doutorado) - Departamento de medicina preventiva, Faculdade de Medicina da Universidade de São Paulo, São Paulo, [periódico na Internet] 2001. [acessado 2013 jun 19] Disponível em: http://mulheres.org.br/parto/tela_cheia/Doutorado\%20\%20Carmen\%20Simone\%20Grilo\%20Diniz.pdf

DUARTE, L. F. D. Indivíduo e pessoa na experiência da saúde e da doença. Ciência \& Saúde Coletiva. 8 (1): 173-183, 2003 [periódico na Internet] [acessado 2013 out 26] Disponível em: http://www.scielo.br/scielo.php?script=sci_arttext\&pid=S1413$81232003000100013 \& \operatorname{lng}=$ en. http://dx.doi.org/10.1590/S1413-81232003000100013.

DOMINGUES, R. M. S. M. Acompanhantes familiares na assistência ao parto normal: a experiência da maternidade Leila Diniz. Rio de Janeiro: Fundação Oswaldo Cruz, 2002. 212 p. Dissertação (Mestrado) - Escola Nacional de Saúde Pública. Departamento de Endemas, ambiente e Sociedade, Fundação Oswaldo Cruz, Rio de Janeiro, [periódico na Internet] 2002. [acessado 2013 abr 25]. Disponível em: http://www.arca.fiocruz.br/bitstream/icict/5214/2/508.pdf

DOMINGUES, R. M. S. M.; SANTOS, E. M.; LEAL, M. C. Aspectos da satisfação das mulheres com a assistência ao parto: contribuição para o debate. Caderno de Saúde Pública, 20 (Supl. 1): S52-S62, 2004 [periódico na Internet] [acessado 2013 jul 26]. Disponível em: http://www.scielo.br/scielo.php?script=sci_arttext\&pid=S0102-

311X2004000700006\&lng=pt. http://dx.doi.org/10.1590/S0102-311X2004000700006

DONELLI, T. M. S. O parto no processo de transição para a maternidade. Porto Alegre: UFRGS, 2003. 175 p. Dissertação (Mestrado) - Programa de Pós-Graduação em Psicologia do Desenvolvimento, Universidade Federal do Rio Grande do Sul, Porto Alegre, [periódico na Internet] 2003. [acessado 2013 mar 26]. Disponível em: http://www.lume.ufrgs.br/bitstream/handle/10183/4122/000397252.pdf?sequence=1

Descortinando a vivência emocional de mulheres em um centro obstétrico: uma investigação sobre o parto através da aplicação do Método Bick. Porto Alegre: UFRGS, 2008. 195 p. Tese (Doutorado) - Programa de Pós-Graduação em Psicologia do Desenvolvimento, Universidade Federal do Rio Grande do Sul, Porto Alegre, [periódico na Internet] 2008. [acessado 2013 mar 23]. Disponível em: http://www.lume.ufrgs.br/bitstream/handle/10183/17843/000725559.pdf? sequence=1 HELMAN, C. G. Cultura, saúde e doença. $4^{\mathrm{a}}$ ed. Porto Alegre: Artmed, 2003. 
HOGA, L. A. K.; PINTO, C. M. S. Assistência ao parto com a presença do acompanhante: Experiências de profissionais. Investigación y Educación en Enfermaría, 25(1): 74-, 2007 [periódico na Internet] [acessado 2013 Ago 10]. Disponível em: http://www.scielo.org.co/scielo.php?script=sci_arttext\&pid=S012053072007000100008\&lng=en.

HOTIMSKY, S. N, ALVARENGA, A. T. A definição do acompanhante no parto: uma questão ideológica? Revista Estudos Feministas, Ano 10, 2 semestre de 2002, p.461-481. [acessado 2013 mai 20]. Disponível em: http://www.scielo.br/pdf/ref/v10n2/14971.pdf

LEÃO, V. M.; OLIVEIRA, S. M. J. V. O papel da doula na assistência à parturiente. REME - Revista Mineira de Enfermagem, 10 (1)24-29, jan./mar., 2006. [periódico na Internet] [acessado 2013 mar 12] Disponível em: http://www.gestamater.com.br/site/images/pdf/art_doulas/o\%20papel\%20da\%20doula\%20na $\% 20$ assitencia\%20a\%20parturiente\%20rev\%20de\%20enferm.pdf

MALDONADO, M. T. Psicologia da Gravidez: parto e puerpério. $16^{\mathrm{a}}$ ed. São Paulo: Saraiva, 2002.

MOTT, M. L. Assistência ao parto: do domicílio ao hospital (1830-1890). Projeto História, São Paulo, (25), dez. 2002. [periódico na Internet] [acessado 2013 mai 15]. Disponível em: http://revistas.pucsp.br/index.php/revph/article/view/10588/7878

MOTTA, C. C. L. Crepaldi MA. O pai no parto e apoio emocional: a perspectiva da parturiente. Paidéia, Ribeirão Preto, v.15, n.30, pp.105-118, jan.-abr., 2005 [periódico na Internet]. [acessado 2013 ago 10]. Disponível em: http://www.scielo.br/scielo.php?script=sci_arttext\&pid=S0103-

863X2005000100012\&lng=en\&tlng=pt. 10.1590/S0103-863X2005000100012

NAGAHAMA E. E. I. Santiago SM. A institucionalização médica do parto no Brasil. Ciência \& Saúde Coletiva, 10(3): 651-657, 2005 [periódico na Internet] [acessado 2013 set 26] ; Disponível em: http://www.scielo.br/scielo.php?script=sci_arttext\&pid=S1413$81232005000300021 \& \operatorname{lng}=$ en. http://dx.doi.org/10.1590/S1413-81232005000300021.

NAKANO, A. M. S.; SILVA, L. A.; BELEZA, A. C. S.; STEFANELLO, J.; GOMES, F. A. O suporte durante o processo de parturição: a visão do acompanhante. Acta Paulista de Enfermagem, 20(2): 131-137, 2007. [periódico na Internet] [acessado 2013 abr 26]. Disponível em: http://www.scielo.br/scielo.php?script=sci_arttext\&pid=S010321002007000200004\&lng=en. http://dx.doi.org/10.1590/S0103-21002007000200004

ORGANIZAÇÃO MUNDIAL DA SAÚDE (OMS). Maternidade segura. Assistência ao parto normal: um guia prático. Brasília; 1996. (OMS/SRF/MSM).

PERROT, M. Minha história das mulheres. 2a ed. São Paulo: Contexto, 2012.

RAMALHO, A. A. A experiência de sentir-se respeitada durante o trabalho de parto no Hospital. LISBOA: Universidade de Lisboa, 2009, 211 p. Tese (Doutorado) - Programa de Doutoramento em Enfermagem, Universidade de Lisboa, Lisboa, [periódico na Internet] 2009 [acessado 2013 set 29]. Disponível em: http://repositorio.ul.pt/bitstream/10451/1848/1/21687_ulsd057996_td.pdf 
SABINO, A. F. M. Tríade gestante-acompanhante-maternidade e a interação para o parto humanizado. Fortaleza: 2010. Escola de Saúde Pública do Ceará Paulo Marcelo Martins 35 p. Projeto de Intervenção - Especialização de Enfermagem Obstétrica (Especialização) - Escola de Saúde Pública do Ceará Paulo Marcelo Martins, Fortaleza, 2010.

SOIFER, R. Psicologia da gravidez, parto e puerpério. Porto Alegre: Artes Médicas, 1980. STORTI, J. P. L. O papel do acompanhante no trabalho de parto e parto: expectativas e vivências do casal. Riberão Preto: USP, 2004. 118 p. Dissertação (Mestrado) - Escola de Enfermagem. Departamento Materno Infantil e Saúde Pública, Universidade de São Paulo, Ribeirão Preto, [periódico na Internet] 2004. [acessado 2013 mai 17]. Disponível em: http://www.teses.usp.br/teses/disponiveis/22/22133/tde-13102004-152521/pt-br.php

SOUZA, K. R. F.; DIAS, M. D. História oral: a experiência das doulas no cuidado à mulher. Acta Paulista de Enfermagem, 23( 4 ): 493-499, 2010. [periódico na Internet] [acessado 2013 jun 26]. Disponível em: http://www.scielo.br/scielo.php?script=sci_arttext\&pid=S0103$21002010000400008 \& \operatorname{lng}=$ en. http://dx.doi.org/10.1590/S0103-21002010000400008.

SPINK, M. J. P. Psicologia Social e Saúde: saberes e sentidos. 9ª ed. Petrópolis, Rj: Vozes, 2013.

STERN, D. N. A constelação da Maternidade: o panorama da psicoterapia pais/bebê. Porto Alegre: Ates Médicas, 1997.

SZEJER, M; STEWART, R. Nove meses na vida da mulher: uma aproximação psicanalítica da gravidez e do nascimento. São Paulo: Casa do Psicólogo, 1997.

TORNQUIST, C. S. Armadilhas da Nova Era: natureza e maternidade no ideário da humanização do parto. Revista Estudos Feministas, Florianópolis, v.10, n.2, jul., 2002 [periódico na Internet] [acessado 2013 abr 02]. Disponível em: http://www.scielo.br/pdf/ref/v10n2/14972

Data de recebimento: 25/04/2016.

Data de aceite: 01/11/2017.

\section{Sobre as autoras:}

Claudia Tomasi Vendrúscolo, graduada em letras e em psicologia; tem especialização em terapia intensiva, ênfase em oncologia e controle de infecção hospitalar, pelo Centro Universitário Franciscano; possui especialização em literatura brasileira, pela UNIFRA. Endereço Eletrônico: claudia.tv@ bol.com.br

Cristina Saling Kruel é psicóloga, especialista em psicomotrocidade (UNISC) e especialista em psicologia clínica-infância e família (UFRGS). É mestre em Psicologia (URFRG) e doutora em Distúrbios da Comunicação Humana (UFSM). Atualmente é professora no Centro Universitário Franciscano (UNIFRA). Endereço Eletrônico: cristinaskruel@ gmail.com 